\title{
Cruzar las fronteras: el sujeto itinerante y las migraciones objetivas y subjetivas
}

\author{
Graciela N. Ricci` \\ Universitá di Macerata
}

\begin{abstract}
Resumen
Este artículo presenta algunas reflexiones sobre la dinámica de confines: de las fronteras histórico-geográficas a las fronteras perceptivas. También observa los procesos centrífugos y centrípetos en la identidad del sujeto itinerante y la mirada del sujeto en las migraciones objetivas y subjetivas. Se plantea un ejemplo literario de búsqueda y de cambio en las fronteras perceptivas y trascendentes: el cuento «La rosa de Paracelso» de J.L. Borges

\section{Palabras clave}

- Identidad · Fronteras · Migraciones · Perspectivas · Trascendencia Borges · Cábala
\end{abstract}

\begin{abstract}
This article offers some considerations about the dynamics of the borders, from the historical and geographical borders to the perceptive ones. Also, it looks into the centrifugal and centripetal processes that shape the identity of the migrating subject and their perspective in both objective and subjective migration processes. To illustrate these motions, this article offers a literary example of the processes of searching and change in perceptive and transcendent borders by tackling Borges' tale «La Rosa de Paracelso».

\section{Keywords}

- Identity - Frontiers - Migrations - Perspectives - Transcendence . Borges $\cdot$ Kabbalah
\end{abstract}

\footnotetext{
- Catedrática de Literatura Española y Directora de grado, post-grado y SISS en Università de Macerata. Docente en la Universidad Católica y en Instituto Modelli di Comunicazione de Milán. Co-fundadora de Heteroglossia (1985). PH.D. en Psicología (Universidad Bruselas). Premios Fondo Nacional de las Artes (Bs. As. 1973) y Escritores de la Provincia (Santa Fe, 1977). Ha publicado numerosos volúmenes de ensayos de literatura y psicología en Italia, Argentina, España, Francia, Alemania y México.
} 


\section{Fronteras centrípetas y centrífugas del sujeto itinerante. Algunas teorías}

El título de este trabajo toca dos temáticas importantes conectadas al cruce de fronteras: las migraciones (geográficas, históricas, culturales, psicológicas, dimensionales...) y el concepto de identidad en el sujeto itinerante, que tiene que ver con las fronteras de adentro y las fronteras de afuera. Dice Bachtin en Dostoevskij:

L'essere dell'uomo è una comunicazione profonda. Essere significa comunicare. Essere significa essere per l'altro e, attraverso l'altro, per sé. L'uomo non possiede un territorio 'interno' sovrano. Egli è integralmente e sempre su una frontiera: guardando dentro di sé, guarda negli occhi altrui o attraverso gli occhi altrui. Non posso fare a meno dell'altro, non posso divenire me stesso senza l'altro. ${ }^{1}$

En las palabras de Bachtin encontramos dos reflexiones importantes: la primera tiene que ver con la interrelación entre dos seres humanos (ser significa comunicar, ser para el otro). Podríamos hablar, en este caso, de una frontera hacia afuera, en contacto con la otredad. La segunda señala que el hombre está siempre situado en una frontera porque aún mirando hacia dentro, en realidad mira a través de ojos ajenos. Estas reflexiones especulares se vuelven más incisivas si están referidas a un sujeto itinerante multicultural y plurilingüe. En efecto, la patria interior de una persona plurilingüe es, más que un territorio definido, una zona de fronteras que define las entradas y salidas de las varias culturas que la atraviesan y las distintas tonalidades de la mirada del sujeto que la percibe. En este sentido, es importante conocer cuál es la opción que define la mirada, porque es la mirada del sujeto la que determina el concepto de identidad. Por ejemplo, cuando observamos el mar ¿vemos la masa líquida como una totalidad estable o vemos las olas que rompen en la orilla, una distinta de la otra? Del mismo modo, cuando hablamos de la identidad de una persona, podemos verla sea como un todo sistémico, como una estructura psíquica constante que permanece más allá de nuestro quehacer cotidiano y nos da la ilusión de ser un "yo» único (definición que reenvía a Aristóteles), sea como un fluir de elementos que cambian (cfr. la famosa frase de Heráclito); en este caso, el sujeto tiene que decidir dónde colocar los confines que lo identifican como algo único e individual. La identidad depende, entonces, de nuestro modo de mirar o de elegir la perspectiva con la cual mirarnos. En la segunda opción, es algo que se construye momento a momento pero que se define a través de un yo.

En el caso de una persona plurilingüe que ha cruzado el océano muy joven cambiando país y continente (y aquí me pongo como modelo paradigmático), que ha viajado por medio mundo primero como estudiante, con regreso, en ese entonces, a la patria de origen (Argentina), y luego ya recibida, ha frecuentado como docente universitario congresos y culturas plurilingües, para regresar ya no a su patria de nacimiento sino a su segunda patria, la de sus ancestros (Italia), la identidad se vuelve un concepto ambiguo e itinerante que cruza constantemente zonas de frontera transgresivas, y en cada una asimila e integra aspectos que enriquecen un fluir de procesos que se funden con sedimentaciones múltiples precedentes. En este tipo de sujeto se acentúa lo que Thomas Sebeok llama «identidad in progress», que se va construyendo mientras se nutre costantemente de negociaciones y apor- 
tes fronterizos, en una búsqueda infinita autoalimentada por filtros neuronales, culturales y experienciales — lo que Sebeok denomina «esfera semiótica» (Sebeok 2001:33) — que conllevan convicciones, principios, valores, sentimientos, ideales, aspiraciones más o menos utópicas y construcciones simbólicas y metafóricas. La esfera semiótica iría más allá, según Sebeok, de los límites del cuerpo físico, por lo cual la identidad de cada uno se plasmaría en un constante proceso de metasemiosis yo-otro, en el cual el yo se transformaría costantemente a través de actos comunicativos interpersonales y/o textos orales y escritos que influirían en las esferas semióticas de los respectivos interlocutores.

Puede ser interesante contraponer a la teoría de Sebeok la que considera que hay tres niveles en la formación de la identidad. Para esta teoría, la búsqueda de la identidad implica dos operaciones opuestas y, al mismo tiempo, conectadas: una de separación y otra de asimilación, que llevan a superponer tres niveles o estratos:

A. Il flusso. Esso si presenta come un mutamento continuo, oscuro e magmatico, radicalmente «distruttivo». Il secondo livello, intermedio (B), è quello delle connessioni, ed è caratterizzato da potenzialità ovvero da elementi alternativi. Da ultimo, il livello più alto $(\mathrm{C})$, sovrapposto ai primi due, è quello delle costruzioni dell'identità. [...] Proprio in quanto costruzione, l'identità si presenta come una riduzione drastica rispetto alle possibilità di connessione $(\mathrm{B})$ e come un irrigidimento massiccio rispetto all'inevitabilità del flusso (A) [...] «De-cidere»l'identità è un «re-cidere» le connessioni (B) che altrimenti la imbriglierebbero e la soffocherebbero. (Remotti 1996:9-10) ${ }^{2}$

Estas disquisiciones nos permiten deducir que la identidad es un concepto subjetivo y complejo que se modifica según la teoría que la sostiene y la/ las culturas de las cuales se nutre. Ello hace que se vuelvan pertinentes preguntas como: ¿quién soy yo desde una perspectiva lingüístico-cultural? ¿Cuál es la relación entre el yo lingüístico, la personalidad global y el nombre que la identifica? Si recordamos la definición que da Bachtin, podemos también preguntarnos: ¿quién es el yo que habla cuando se dirige a un interlocutor? ¿Este yo es el mismo en cualquier acto comunicativo o cambia según el tipo de lengua y de cultura utilizada? Preguntas que surgen a partir de una pregunta raíz: ¿qué significa ser igual a sí mismo? Si tenemos presente que cada lengua es un mundo, las arquitecturas plurilingüísticas de mi yo, que habla varios idiomas sin dificultad, debería poseer universos paralelos. Los componentes híbridos y cosmopolitas, que ocupan los confines de una identidad tejida a través de una pluralidad de lenguas, viajes, culturas y lecturas multilingües, son otredades, en parte conflictivas, que resuenan en el interior de las personas con un pie en dos o más países, como es mi caso y el de tantos exiliados (voluntarios o no), inmigrantes, diplomáticos o gente que ha tenido que residir durante años en varios países y continentes. Esta otredad interior, que se nutre de «disonancias cognitivas ${ }^{3}$ pues funciona como elemento creativo pero también disonante, se vuelve un recurso importante para comprender y aceptar la otredad ajena, porque hace posible una relación inter/ intra-partes que permite iluminar o reflejar zonas semióticas subconscientes de cada interlocutor. Como diría Bachtin, el lenguaje presupone un interlocutor y el discurso del yo, desde esta perspectiva, no es nunca un discurso completamente suyo porque se amplifica reenviando al discurso ajeno, en una relación ininterrumpida entre el pensamiento y la interacción social.

El problema, ya a nivel general, es que hemos entrado demasiado rápidamente en un mundo cuya dinámica evoluciona con ritmo vertiginoso hacia una realidad 
virtual que el cerebro todavía no logra entender completamente, le faltan las estrategias de respuesta adecuada. Las consecuencias parecen ser síntomas depresivos, déficit de atención y de memoria, y enfermedades del sistema inmunológico y/o neurológico por la imposibilidad de controlar la hiperactividad y el exceso de información de la tecnología actual. Eso significa que el yo se encuentra en un espacio mental novedoso pero que resulta en disonancia con un cerebro que reacciona según parámetros ya superados y, en algunos casos, arcaicos. Por eso, para la mayoría de los seres humanos, el nivel de ansiedad psíquica se ha incrementado en forma exasperante, y eso aumenta la confusión en las respuestas que uno puede darse a la pregunta ya formulada: ¿qué significa ser igual a sí mismo? Si pensamos en lo que está sucediendo, en estos momentos, a nivel planetario con la pandemia del coronavirus, a esta pregunta se puede sumar otra tal vez más angustiante: ¿en qué dirección estamos yendo como especie humana?

Algunas teorías concernientes a la identidad, elaboradas por la Universidad de Chicago (Inghilleri 1995:61-62), parecerían dar respuesta a la búsqueda de armonía de la cual el mundo, sobre todo la parte occidental, se está demostrando carente. La teoría, denominada del «fluir de la conciencia o experiencia optimal», ha sido elaborada a partir de reflexiones sobre el proceso de aprendizaje. La Universidad de Chicago ha llegado a la conclusión que la identidad crece en complejidad e integración con un tipo de experiencia subjetiva que asegure al ser humano mayor equilibrio y una dimensión de intensa participación con el universo. El fluir de la conciencia está considerada una experiencia emergente de tipo sistémico que produce un buen equilibrio psico-social (se asemeja, en parte, a ciertas modalidades de comportamiento pertenecientes a culturas amerindias, como la de los indios navajos). Es una experiencia que no está predeterminada por la información que ya posee el sujeto que la vivencia, y lo lleva a aceptar desafíos cada vez más complejos. El equilibrio se logra a partir de una interacción dinámica entre las pruebas y estímulos del contexto y las capacidades que el individuo ha desarrollado a través de las experiencias vividas, dosando en forma armónica la polaridad ansia-apatía en relación con la dialéctica «estímulos externos-recursos interiores» (Ricci 2012:161). Tomemos como ejemplo lo que está sucediendo actualmente a nivel mundial con la pandemia del coronavirus. Algunos han dicho que este fenómeno apocalíptico podría ser interpretado como una especie de prueba que el planeta envía a la especie humana por la destrucción y contaminación que ha provocado y que podría llevar al mundo a una posible sexta extinción de masa. Otros consideran que nosotros podríamos ser el virus y el Covid-19 la reacción inmunitaria del planeta contra la especie humana. Más allá de las teorías, lo que sucede es que, a través de la constante invasión de informaciones de la tecnología actual (TV, whatsapp, youtube y las social networks), la mente humana está siendo «colonizada» por el Covid-19 y es pertinente preguntarse cómo afrontará el ser humano el regreso a la normalidad, que no podrá ser igual a la que era antes. Es aquí donde la capacidad de resiliencia del ser humano se pondrá a prueba, y donde el estado de flow logrado a través de prácticas de mindfulness o afines será importante para aceptar nuevas formas ecológicas de vida que permitan crear un mundo mejor.

Los estudios de neurolingüística han dado un aporte a los de la Universidad de Chicago en lo que concierne el funcionamiento de nuestros sentidos, pues señalan que los mismos han sido programados para percibir un mundo asimétrico y necesitan de él para poder funcionar; resultados confirmados por las teorías de 
M. Lotman sobre la relación de simetría/asimetría y enantiodromía del sistema consciente/inconsciente (Lotman 1980-84) y de I. Matté Blanco sobre la bi-lógica y el inconsciente como conjuntos infinitos (Matté Blanco 1975). Si se quitan las asimetrías, la neurología habla de un fenómeno llamado fusión bi-aural (Demartini 2002), semejante a una voz interior que se da en un estado de gran equilibrio. Lo mismo sucede con la fusión bi-visual y bi-cenestésica que producen un estado alterado de conciencia. Son estados que permiten una gran paz interior y una acrecida conciencia de vigilia y hacen sentir más en contacto con el universo como totalidad viviente. Dichos estados tienen muchos puntos de contacto con lo que enseñan las filosofías orientales y las filosofías herméticas occidentales, y es probable que practicar alguna técnica que permita superar el mundo asimétrico de los sentidos pueda dar más recursos al ser humano para mejorar la calidad de vida y superar las incógnitas del futuro (Ricci 2012:166).

\section{El cruce de fronteras: un modelo histórico}

Como sabemos, en América Latina, y sobre todo en Argentina, la dinámica interrelacional entre fronteras, migraciones (de ida y de vuelta) y plurilingüismo ha sido siempre muy intensa y ha influido en la configuración de los países y en la evolución de las distintas culturas, especialmente a partir del siglo XIX, después de la Independencia de las colonias de España. Las migraciones están también relacionadas con la experiencia de exiliado, más o menos voluntario según los casos, y las dos categorías se conectan con el concepto de identidad, pues se relacionan con fracturas existenciales y con dinámicas sociopsicológicas «fronterizas» como el yo/nosotros, el yo con/contra el Otro, la relación Europa/América y centro/periferia, la puja dialéctica entre la lengua madre y la segunda lengua. Voy a tomar como modelo histórico, en Argentina, un período de mucho movimiento en el fenómeno migratorio, que va desde la década de 1880 — con la subida al gobierno del General Roca, la jerarquización de Buenos Aires a Capital y el inicio del movimiento Modernista- a las postrimerías de la década del 30. Describiré, en forma sumaria por falta de espacio y de tiempo, los aspectos culturales principales que caracterizaron el territorio de «las orillas» bonaerenses de dicho período, porque, además, es allí y en esos años, especialmente en los años 20 , cuando surge la figura de Borges de quien tomaré como ejemplo literario un texto que evidencia el cruce de fronteras dimensionales y perceptivas.

Como he comentado en un trabajo anterior ${ }^{4}$, el término «las orillas» —que se utilizó al principio para definir los márgenes del Río de la Plata y, a partir de esa época, para designar los barrios limítrofes de Buenos Aires - tuvo una gran expansión semántica y llegó a abarcar fronteras no solo geográficas y culturales sino también psicológicas y esotéricas, pues la visión hermética del mundo en esos años adquirió notable importancia en la poética modernista rioplatense: 
Los escritores de esa época fueron protagonistas de un período de gran fervor social, intelectual y pasional, ya sea en la Argentina del primer 900 que en las décadas posteriores del 20 y del 30, y vivieron en los márgenes de un territorio en constante ebullición geográfica, social y anímica. Por tal motivo, tuvieron que luchar con fuerzas poderosas que provocaron crisis existenciales de gran calibre, y si muchos de ellos lograron reconstruir su identidad fragmentada a través de una escritura que puede considerarse en parte autobiográfica, otros sucumbieron a las fuerzas inconscientes y terminaron suicidándose. (Ricci 2016:58) (es el caso de Horacio Quiroga, de Alfonsina Storni, de Lugones, y también de Lisandro de la Torre en política).

El período modernista, que inicia en 1888 con la publicación en Chile de $\mathrm{Azul}$ de Rubén Darío, se distingue no solo por su intensa creatividad periodística y literaria, sino también por los movimientos migratorios que aumentarán la población en poco tiempo, lo mismo que la fusión de lenguas y culturas en las dos orillas de Buenos Aires y Montevideo. En Buenos Aires el movimiento será doble: centrífugo y centrípeto (Assunção, 1998:23-26), y provocará el crecimiento de la denominada Gran Aldea, hoy gigantesca megalópolis, debido no solo al deseo de las clases adineradas de ir a vivir en zonas residenciales para huir de la fiebre amarilla y de las masas de inmigrantes recién llegadas, sino también al enriquecimiento de la alta burguesía patricia por el desarrollo del comercio y del agro, el ingreso de capitales y la cantidad de mano de obra nueva, producto de la gran inmigración. Es el período que se conoce como «Siglo de Oro» porteño, remedando la denominación española, y se extiende hasta la década del 30, cuando se produce el primer golpe militar con Uriburu, se publican los primeros números de la revista Sur fundada por Victoria Ocampo (es de 1931 el primer número), y se entremezclan truhanes y malevos con personajes representativos de gran relieve (algunos suicidas); entre ellos

personajes de la pluma y de la espada que asumieron roles políticos además de literarios, como Mitre, Sarmiento, Roca y Alberdi, y escritores como Lugones, Quiroga, Borges, Storni, Martínez Estrada, que debieron luchar con demonios fronterizos de un inconsciente todavía no oficialmente reconocido. Esa ebullición de ideas y emociones desenfrenadas generó también una intensa creatividad artística y musical con, por ejemplo, Quinquela Martín, Xul Solar y Lino Spilimbergo en la pintura, y Carlos Gardel, Santos Discépolo y Osvaldo Fresedo —entre otros- en el tango. (Ricci, 2016:59)

Los escritores de esos años, movidos por inquietudes interiores, cruzaron más de una vez en nave la vasta frontera oceánica hacia Europa, en busca de una identidad individual y nacional satisfactoria; búsqueda que los llevó a organizar contactos, tertulias y experimentaciones literarias y herméticas en ambos lados del océano ${ }^{5}$. El modernismo se impregnó abundantemente de dichas doctrinas que influyeron, incluso, en sus innovaciones estéticas y exóticas ${ }^{6}$. Los desplazamientos centrífugos y centrípetos por mar y por tierra provocaron una serie de interacciones sociales que convirtieron a Buenos Aires en un crisol de transformaciones cuantitativas y cualitativas ${ }^{7}$. Los aportes del modernismo y la gran heterogeneidad étnica, con las contaminaciones lingüísticas del cocoliche y del lunfardo y los contrastes entre guapismos y vivezas criollas e italianas, modificaron en forma definitiva el tejido social, cultural y lingüístico del país y el estilo arquitectónico de la capital argentina. Modernismo y Modernidad estuvieron muy conectados en ese período, pues vida 
y literatura se percibían casi como un bloque único, por lo que sería mejor hablar de época cultural más que de escuela literaria.

Podemos deducir, entonces, que en muchos escritores de ese período la dinámica del movimiento, entre viajes migratorios, lingüísticos, de exilio y de contactos más o menos extrańos, tuvo que ver con el cruce de fronteras, acuáticas y territoriales: la doble frontera de la ciudad y de la pampa, y la doble frontera continental y europea, uruguaya y argentina, son el escenario agitado donde el Río de la Plata, como símbolo del fluir del tiempo, adquiere un rol basilar. El río era ya, desde la Antigüedad, una imagen metafórica conocida y utilizada y ocupó un lugar significativo en numerosas literaturas:

Lo encontramos en el Rig Veda y en los ríos alquímicos de la China milenaria, en las reflexiones de Heráclito, en las mitologías griegas y egipcias, con Poseidón (en su origen, dios de ríos y manantiales y luego dios del mar) y con Proteo (dios egipcio del agua de "formas inasibles», como diría Borges). (Ricci 2016:62).

El río fue un arquetipo poderoso desde tiempos inmemoriales pues, como bien dijo Jung: «Todo arquetipo...es una forma externa de religión [...], se identifica completamente con las representaciones externas, pero permanece inconsciente como factor anímico» (Jung, 1977:24). De allí que adquiera también connotaciones simbólicas y trascendentes y se lo encuentre en las principales mitologías como entrada o parte del mundo ultraterreno: el Tigris, en el imperio neoasirio (1100 A.C.), era la entrada al Hades; en la antigua Grecia el Aqueronte, junto con el Estigia, el Cocito, el Flegetonte y el Lete, eran considerados los cinco ríos del reino de los muertos; el lago de Averno (cerca de Pozzuoli, Italia) era una puerta al Hades y el antepasado de Eneas se dirige al lago para bajar a los infiernos... (Zimmermann, 2019:283). Pero más allá de todas las menciones mitológicas y literarias del término a lo largo del tiempo, en Latinoamérica —especialmente en Buenos Aires y en el litoral santafesino-, el río, con sus orillas, adquiere connotaciones particulares porque fue utilizado como imagen fundacional de la patria y, por lo tanto, en relación estrecha con la identidad (recordemos, en ese período, la famosa poesía de Borges: «Fundación mítica de Buenos Aires» que inicia con los conocidos versos: «¿Y fue por este río de sueñera y de barrio/ que las proas vinieron a fundarme la patria?»).

La patria, ayudada por las connotaciones simbólicas del río, se convierte en un crisol de miradas híbridas, de sensaciones y recuerdos nostálgicos, en un sincretismo de lenguas y culturas que componen un u-topos, un no-lugar donde los sueños recrean un territorio diferente que ya no será nunca más la patria de nacimiento, como dice Borges en estos versos:

En aquel Buenos Aires que me dejó, yo sería un extraño.

Sé que los únicos paraísos no vedados al hombre son los paraísos perdidos.

Alguien casi idéntico a mí, alguien que no habrá leído estas páginas,

lamentará las torres de cemento y el talado obelisco. («Buenos Aires», en La cifra) 


\section{Borges y "las orillas»}

Es en 1921 que Borges vuelve a Argentina desde Europa, entusiasmado por el Ultraísmo; luego de fundar con sus amigos Prisma y Proa, publica su primer libro: Fervor de Buenos Aires (1923), donde se encuentra, como señala Rodríguez Monegal, «la mejor poesía producida por el ultraísmo argentino» (1993:158). Borges inicia con ese libro, al que seguirán Luna de enfrente (1925) y Cuadernos de San Martin (1929), la búsqueda de una síntesis entre formas vanguardistas y contenidos nacionales. Según comenta Rodríguez Monegal, Borges en esa época estaba seriamente interesado en recuperar algunos elementos perdidos del pasado argentino. Es así que se pregunta: «¿Cuándo habrá un patriotismo criollo, que no sepa ni de Atahualpa, ni de don Diego de Mendoza, ni de Maurice Barrés?» (Borges 1925:207). En realidad, como dice María Esther Vázquez,

No era la ciudad entera la que lo conmocionaba. [...] Lo enamoraba la mitología sensual de las orillas, pobladas por las sombras de los cuchilleros muertos, el tango oído en los conventillos, los naipes mugrientos jugados en almacenes pintados de un rosa fuerte, el velorio humilde de alguien desconocido, el inconfundible olor del mate...Y Borges, deslumbrado, salió a descubrir la ciudad. (Vásquez, 1996:73).

Borges, en esos años, se hace amigo y queda impactado por Macedonio Fernández, de quien dice: «Felicidad aquella de saber que en una casa de Morón o del Once había un hombre mágico cuya sola existencia despreocupada era más importante que nuestras venturas o desventuras. Esto lo sentí yo, lo sentimos algunos, esto no puedo comunicarlo» (cit. por Galasso, 1998:54). En el mismo período, Raúl Scalabrini Ortiz, que trató mucho a Borges a través de Macedonio, dice de Borges:

Hombre pleno de antinomias es este Jorge Luis. Yo no sé cómo él sofoca o coordina los movimientos antagónicos de su espíritu: la minuciosa precisión de su razonamiento y la invariable candidez de su sensibilidad: su espíritu andariego y su avidez de erudicción. Muchos paisajes ha visto sin que se adentraran en su pupila. [...] Pero es en la prosa donde Borges se agranda. Ha renovado la adjetivación trocando los epítetos ya desgastados por otros cuya novedad muestra más claramente su carácter metafísico. (Scalabrini Ortiz, en El diario de Paraná, 30/11/1926)

De estas citas quisiera rescatar dos cosas: la primera es la palabra «mágico» referida a Macedonio, porque creo que la figura de Paracelso podría haber surgido, además de la incursión de Borges en las lecturas de De Quincey y del mismo Paracelso, de su gran admiración por ese personaje casi mítico que fue Macedonio, quien al autodefinirse, interpretaba intuitivamente el sentir de Borges mismo ${ }^{8}$. La segunda cosa es el comentario que hace Scalabrini Ortiz de la prosa de Borges que, en ese período, comienza a perder sus connotaciones patrióticas para ir volcándose hacia lo fantástico-metafísico. Es verdad que la cuestión fundamental para el Borges de esa década entre el 20 y el 30, era dar una voz propia y nueva a esa patria que lo preocupaba, una voz nueva con un nuevo lenguaje ${ }^{9}$. Pero algo sucede a Borges hacia el final de esos años (1929/1932) que lo hace pasar de su horizonte nacionalista y 
criollista a un internacionalismo universal. Como bien dice V. Teitelboim: «Todo indica que algo grave sucedió, modificando su visión [la de Borges] de la literatura y el curso de su existencia ¿Qué fue exactamente?» (Teitelboim 1996:51). En ese momento, Borges encuentra a Victoria Ocampo y la revista Sur. Sin embargo, su vida es muy solitaria, algunos consideran que hubo desilusiones amorosas (ivi), e incluso que en 1934 intentó suicidarse pero que no tuvo el coraje necesario. Según Vazquez, «la idea del suicidio lo persiguió por años» (1996:147). La cuestión es que Borges, después de ese período "patriótico", abandona todo interés por los libros que ha publicado entre 1923 y 1930, por lo cual en 1938, luego de la muerte de su padre y del accidente que lo tuvo entre la vida y la muerte ${ }^{10}$, y después de un largo silencio, se transforma en «el otro» Borges, y su literatura se convierte a la literatura fantástica y metafísica.

He comentado, si bien muy brevemente, el primer período del Borges escritor porque, en realidad, Borges transcurre sus últimos años por la senda ya elegida a mediados de los años treinta, como bien comenta Norberto Galasso (1998:173). Por lo tanto, creo que el cuento de 1977 que voy a analizar tiene sus raíces en aquellos años. Además, son en gran parte las lecturas que efectúa en la biblioteca de su padre en la casa de calle Serrano (Palermo), las que lo proveen de toda la literatura hermética que le permitirá, años después, en edad madura, escribir «La rosa de Paracelso", y mucho antes, su poema «El golem», sus ensayos cabalísticos, y las varias poesías a la arquetípica rosa de la Alquimia. Recordemos que Borges era un apasionado de Cábala y de Alquimia; ya en 1931 había publicado en Discusión un capítulo del título: «Una vindicación de la Cábala» (1989:75-91), en la cual comentaba que no quería "vindicar la doctrina, sino los procedimientos hermeneúticos o creptográficos [sic] que a ella conducen» (1989:55); también había conocido personalmente a Gershom Scholem en sus viajes a Jerusalén, y leído muchos textos sobre esos temas, entre ellos los de R. Lulio, Meyrink, el mismo Scholem, y también Hohenheim, más conocido como Paracelso.

\subsection{Borges y "La rosa de Paracelso»}

La primera edición del cuento es de 1977, aunque algún crítico la hace datar de $1983^{11}$ y, como el título lo indica, la trama toma como protagonista la figura del famoso médico suizo y alquimista Philippus Aureolus Theophrastus Bombast de Hohenheim (1493-1541), cuya visión filosófica de la vida modificará notablemente la medicina oficial occidental del Renacimiento. Paracelso adquiere los primeros rudimentos de medicina, cirugía y alquimia de su padre, también médico; pero luego de diplomarse enViena y doctorarse en Ferrara, su vida se vuelve un constante vagabundear por Europa y Medio Oriente. En Basilea conoce a Erasmus y cura al humanista Frobenius, pero sus curaciones casi «mágicas» de enfermos terminales hacen que los médicos tradicionales lo acusen de charlatanería e impostura (episodio que Paracelso menciona vagamente en el cuento que nos ocupa). Fallece en 1541, en forma imprevisible (tal vez por una emboscada) en Salzburg. 
Paracelso fue un gran creyente, aunque no del tipo tradicional: el concepto del astrum in corpore era su idea capital, y colocaba el fundamento de toda sabiduría y arte en la raíz divina que genera el mundo. Era llamado «el Lutero de la medicina» por sus fórmulas innovadoras (con técnicas alquímicas, anticipó la medicina homeopática). De él se dice, entre otras cosas, que logró transmutar el plomo en oro con procedimientos alquímicos. En su libro Il fondamento della sapienza (Torino: Il leone verde 1998) Paracelso afirma:

Noi, invero, siamo Dio, e dunque dobbiamo da soli sperimentare cio che è in noi: egli è di se stesso e non nostro; ci ha formato il corpo, dato la vita e insieme la sapienza, e da Lui provengono tutte le cose. (1998:24); [...] L’uomo non impara nulla, ma risveglia e richiama solo ciò che è sepolto in lui (31); Come sulla terra noi dobbiamo avere in Dio il nostro specchio [...] così nella sapienza dobbiamo manifestare Dio (35); Dio è potente e vuole manifestare la sua potenza nell'arte e nella sapienza sia agli uomini sia agli angeli. (41) Non dobbiamo seguire gli antichi, ma radicarci nella fede e porre e lasciar crescere il nostro seme sotto il sole (98). ${ }^{12}$

Las frases que he seleccionado del libro de Paracelso pueden servir como base para comprender mejor el cuento, que está conectado a un sujeto itinerante (el aspirante discípulo) en busca de su identidad; sujeto que se supone ha ya superado metas concretas (la profesión, la familia, el dinero, poder, éxitos), por lo cual pretende, en su encuentro con Paracelso, lograr una meta más sutil y ambiciosa: una transformación profunda que lo ponga en contacto con su verdadera Esencia. Es allí donde el cruce de fronteras toca una dimensión sagrada que podríamos definir como «esotérica» teniendo en cuenta la etimología de la palabra, del griego esoterikós: «interior»; término usado para indicar enseñanzas espirituales ${ }^{13}$ reservadas a un círculo restringido de discípulos.

En realidad, también en las grandes religiones monoteístas tradicionales, como en las del Oriente Extremo y Medio, existía —además de la sección institucional, exotérica- una sección esotérica conectada a ritos y saberes reservados. También en todas ellas, como en las grandes tradiciones sagradas del mundo, se describe el proceso de crecimiento espiritual y de búsqueda de la Esencia o Ser profundo con las mismas imágenes primordiales y/o arquetípicas, que mencionan un Estado de comunión con lo divino que trasciende la mente —y reenvían a las Ideas platónicas - al cual dan distintos nombres: Piedra filosofal, Elixir de vida, Diamante, Rosa, Niño de oro, etc. (Jung 1977). En «La rosa de Paracelso» Borges elige una de esas imágenes arquetípicas: la Rosa, símbolo del microcosmos (y de muchos de sus poemas); pero además, el cuento toca los temas principales de este trabajo: el problema de la identidad, ya mencionado, y los varios cruces de fronteras objetivos y subjetivos: yo/otros, percepción/ intuición, palabra/silencio, profano/ sagrado. Si pensamos en la pasión de Borges por los espejos y por las disciplinas herméticas, se entenderán mejor las dos posibles interpretaciones que pueden darse al final paradójico del cuento. Como dice Ricardo Piglia en su ensayo «Tesis sobre el cuento»: «un cuento siempre cuenta dos historias» (Piglia 2001:105) y agrega:

Cada una de las historias se cuenta de modo distinto. Trabajar con dos historias quiere decir trabajar con dos sistemas distintos de causalidad. Los mismos acontecimientos entran simultáneamente en dos lógicas narrativas antagónicas. Los elementos de un cuento tienen doble función y son usados de manera diferente en cada una de las dos historias ${ }^{14}$. 


\subsection{Análisis del cuento}

Resumo brevemente la trama del cuento de Borges: Paracelso recibe una noche la visita de un aspirante discípulo que había caminado tres días y tres noches para llegar a su casa pues su intención era estudiar con él el Arte, o sea, el camino alquímico que lleva a la Piedra filosofal. Para ello, le trae de regalo un talego con monedas de oro para pagar sus enseñanzas, y una rosa encarnada para pedirle una demostración de sus capacidades mágicas. Pero Paracelso le responde: «El camino es la Piedra. El punto de partida es la Piedra. Si no entiendes estas palabras, no has empezado aún a entender. Cada paso que darás es la meta» (20). El joven lo mira con recelo e insiste en su pedido porque, antes de recorrer el sendero con el maestro, quisiera una prueba de sus capacidades. Y se justifica diciendo que todos afirman que Paracelso es capaz de quemar una rosa y hacerla renacer de las cenizas por obra de su Arte, y que él quisiera ser testigo de ese prodigio. Pero el maestro responde: «Eres muy crédulo [...] No he menester de la credulidad; exijo la fe». Y más adelante agrega:

Si yo lo hiciera, dirías que se trata de una apariencia impuesta por la magia de tus ojos. El prodigio no te daría la fe que buscas: deja, pues, la rosa. [...] Además, ¿quién eres tú para entrar en la casa de un maestro y exigirle un prodigio? ¿Qué has hecho para merecer semejante don? (23).

El joven insiste y le dice que creerá en el testimonio de sus ojos; luego toma la rosa y la arroja a las llamas, esperando que el maestro confirme sus poderes de alquimista y la haga resurgir. Paracelso no acepta el desafío y responde con llaneza: «Todos los médicos y todos los boticarios de Basilea afirman que soy un embaucador. Quizá están en lo cierto. Ahí está la ceniza que fue la rosa y que no lo será» (24). Entonces el joven, sintiendo compasión por quien consideraba un charlatán o un mero visionario, le explica que le ha faltado la fe y que volverá cuando será más fuerte, bien sabiendo que no volverían a encontrarse. Y dado que dejarle las monedas de oro hubiera sido humillante, se las lleva con él. El cuento termina con estas palabras: «Paracelso se quedó solo. Antes de apagar la lámpara y de sentarse en el fatigado sillón, volcó el tenue puñado de ceniza en la mano cóncava y dijo una palabra en voz baja. La rosa resurgió» (24).

Tomemos nota de las circunstancias en que se desarrolla el encuentro: es al atardecer que llega el sujeto itinerante, luego de tres días y tres noches de caminata. Por lo tanto, está cansado y el cuento lo dice. La casa posee una planta baja y un sótano de dos habitaciones en el que hay una chimenea, "polvorientos alambiques y el atanor» (19) (como los laboratorios alquímicos «ora et labora», una parte para la plegaria y otra para el trabajo); en total, se repite el tres, número sagrado en las disciplinas herméticas. Al laboratorio subterráneo se accede trámite una escalera caracol (que recuerda la espiral logarítmica). Paracelso está sońoliento y "fatigado» (fatiga que se extiende al sillón de la frase final, en una feliz hipálage que Borges amaba mucho), y en su distracción se olvida de rezarle a su «indeterminado Dios, a cualquier Dios» para que le mande un discípulo.

Toda esta primera descripción introduce al lector a un clima onírico de claroscuros (ambientales y psíquicos) que oscila entre la vigilia y el sueño. En ese mo- 
mento llega no un discípulo, como hubiera deseado el maestro, sino un aspirante a discípulo. Y comienza el diálogo entre los dos...

El cuento, como muchos otros cuentos de Borges, en su aparente simplicidad es muy complejo, y encierra toda una serie de referencias filosóficas y religiosas; por lo tanto, su interpretación no es unívoca y tiene que ver tanto con la identidad del maestro y del joven como con la frontera posible entre dos mundos, uno visible y otro invisible. Además, señala una dualidad especular implícita que se transforma en desdoblamiento: el maestro, a través del diálogo con el joven, oscila entre la posibilidad de ser un sabio o mago, como piensan sus admiradores, o un charlatán o visionario, como afirman sus detractores. También el final, muy sugestivo, deja al lector la posibilidad de dudar sobre los propósitos de Borges: la rosa que resurge cha superado realmente la frontera entre los dos mundos, material/ inmaterial (o visible/ invisible, o también temporal/ eterno), o es un efecto perceptivo que Borges ofrece al lector para activar su discernimiento?

En realidad, el final (y más bien, todo el cuento) alude a uno de los instrumentos fundamentales de las disciplinas herméticas: el lenguaje simbólico. Y eso ya se puede deducir del epígrafe que Borges ha elegido para este relato: «De Quincey: Writings XIII, 345». Como él mismo confiesa en una entrevista con Antonio Carrizo, fue el episodio de Paracelso que se jactaba de poder resucitar una rosa de las cenizas, leído en uno de los catorce volúmenes de De Quincey, que le inspiró el cuento (Carrizo, 1982:59). A este episodio también se refieren los versos de Fervor de Buenos Aires en la edición tardía de 1969: «La rosa/ la inmarcesible rosa que no canto,/ la que es peso y fragancia,/ la del negro jardín en la alta noche,/la de cualquier jardín y cualquier tarde,/ la rosa que resurge de la tenue/ ceniza por el arte de la alquimia». Borges admiraba mucho a De Quincey que, como él, era un «buscador» metafísico (como admiraba también a Coleridge y Poe, todos adictos al opio). En esa página 345, De Quincey menciona por segunda vez a Paracelso cuando comenta: «Insolent vaunt of Paracelsus, that he would restore the original rose or violet out of the ashes settling from its combustion - that is now rivaled in this modern achievement ${ }^{15}$. De Quincey se refiere a la capacidad de la química de su tiempo de reconstruir la escritura borrada de los pergaminos sobreescritos. De aquí un primer paralelo entre la rosa y la escritura. Pero en realidad, todo el cuento tiene que ver con el poder creativo de la escritura según la tradición cabalística, la cual considera que «el idioma no es producto de conjeturas que animarían la búsqueda de secretos divinos, sino un producto divino que permite a los iniciados penetrar el mundo donde las conjeturas humanas se transforman en las certidumbres de la Deidad" (Sosnowski, 1976:23). De allí que, para la Cábala, descubrir los misterios de la escritura es posible solo a quien ha experimentado en primera persona la verdad mística encerrada en la alusión simbólica.

Borges hace suya (y generaliza a todos los textos) la idea que la lectura debe estimular en el lector una visión más profunda del universo, por lo cual, en este cuento hace que el aspirante discípulo no pueda superar la prueba hasta que no logre entender el lenguaje alusivo que le ofrece el maestro, y comprender, además, como enuncian las disciplinas herméticas, que la realidad es un sistema de símbolos que hay que saber descifrar pues las palabras no pueden transmitir la esencia inefable de las cosas. Borges hace decir a Paracelso en sus reflexiones: 
Si arrojamos esta rosa a las brasas, creerías que ha sido consumida y que la ceniza es verdadera. Te digo que la rosa es eterna y que solo su apariencia puede cambiar. Me bastaría una palabra para que la vieras de nuevo. (22)

Y agrega más adelante: «Hablo del que usó la divinidad para crear los cielos y la tierra y el invisible Paraíso en que estamos, y que el pecado original nos oculta. Hablo de la Palabra que nos enseña la ciencia de la Cábala» (23). En estas frases se hace evidente que Borges alude a dos aspectos importantes de la Cábala: uno concerniente el lenguaje como fuente ontológica del universo; el otro, la escritura simbólica como alternativa al silencio del místico. La referencia al Paraíso invisible reenvía, según creo, a los cuatro niveles de interpretación de la Sagrada Escritura: Pesat, Deras, Remez, Sod, cuyas iniciales constituyen el P(a)R(e)D(e)S o Paradiso (Sosnowski, 1976:32-33). Por lo que concierne la escritura simbólica, Borges expresa el mismo concepto en forma explícita en una disertación del título El libro (1979):

En todo Oriente existe aún el concepto de que un libro no debe revelar las cosas; un libro debe, simplemente, ayudarnos a descubrirlas. A pesar de mi ignorancia del hebreo, he estudiado algo de la Cábala y he leído las variaciones inglesas y alemanas del Zohar y el Sefer Yetzira. Sé que esos libros no están escritos para ser entendidos, están hechos para ser interpretados, son acicates para que el lector siga el pensamiento. (O.C. 1989, IV:166)

También en una entrevista que le hace Jaime Alazraki, en su libro sobre la Cábala, Borges se refiere al lenguaje alusivo y confirma lo expresado indirectamente en el cuento:

En el lenguaje de los místicos, como en cualquier otro lenguaje, las palabras presuponen una experiencia compartida. Por ejemplo, si utilizo la palabra rojo, debo suponer que usted conoce ese color. Otras palabras, por otra parte, se refieren a experiencias íntimas que solo pueden ser sugeridas a través de metáforas (Alazraki, 1988:55, la traducción es mía).

Las palabras de Borges aclaran el motivo por el cual Paracelso se niega a hacer resurgir la rosa ante el joven: si el maestro le hubiera dado la prueba de su poder sobre la materia, la comunicación hubiera sido directa, como sucede con el lenguaje científico, y no indirecta como en el lenguaje hermético, y el aspirante discípulo hubiera dejado de esforzarse para intuir la esencia escondida de las cosas en los símbolos del universo. Pero al joven, impaciente y fatigado, le falta esa fe inquebrantable, exigida por el maestro, que puede darle acceso a la experiencia mística que solo puede ser percibida con los ojos del espíritu (por eso, no es un discípulo sino un aspirante a serlo, como Borges precisa). Este episodio recuerda otro del Evangelio de San Juan (20,19-31), en el cual el discípulo Tomás, llamado Dídimo, no cree hasta que no toca las heridas de Jesús, y este le dice: «Has creído porque me has visto [y tocado mis heridas]; beatos los que no han visto y han creído» (tengamos presente que el joven se llama Johannes: Borges no deja nada librado al azar).

Lo que entonces Borges transmite, a través de las peripecias del sujeto itinerante, es que - desde la perspectiva hermética — un aspirante discípulo no puede ser aceptado como discípulo hasta que no tenga la suficiente energía interior (hoy diríamos «resiliencia») para recuperar la fe en sí mismo y en el lenguaje alusivo sugerido por el maestro; además debe poder llegar a intuir que su incapacidad 
de encontrar un sentido a las palabras del maestro, señala sus limitaciones para comprender las claves secretas que Dios ha colocado en el universo. Por eso Paracelso debe insistir en sus reflexiones: «Te digo que la rosa es eterna y que solo su apariencia puede cambiar. Me bastaría una palabra para que la vieras de nuevo» (Borges 1983:22). Aquí se reafirma el poder absoluto cabalístico de la Palabra sagrada que puede hacer revivir el golem y resurgir la rosa. Resulta comprensible, entonces, la actitud de Paracelso ante el joven: la Rosa esencial y arquetípica es siempre eterna, pero solo es visible a quien está despierto interiormente. El problema es que el lenguaje alusivo requiere, en primer lugar, una mente profunda, calma y descansada para poder descifrar con claridad los mensajes de la dimensión invisible. En el cuento, la fatiga es doble: el joven, que además de estar cansado, es superficial, no tiene la capacidad para intuir el mensaje del maestro, y este pareciera tener también en ese momento, poca energía pues le pide a «cualquier Dios» que le mande un discípulo y se olvida de rezar (al estar «distraído» le falta, además, la concentración suficiente para transmitir, al que todavía no es discípulo, las condiciones necesarias para poder hollar el sendero). Por lo tanto, el hilo invisible que conecta todo el relato resulta ser no solo el tema del confín —en modo especial el cruce o pasaje de la temporalidad a la eternidad, que ha sido siempre nuclear en las reflexiones de Borges - sino también el tema de la búsqueda y del poder generativo del lenguaje simbólico.

\section{Conclusiones}

Cierro este trabajo con algunas reflexiones que permiten conectar la primera parte con la segunda. Las neurociencias enseñan que nosotros percibimos la realidad a través de filtros neurológicos, culturales y experienciales que impiden a la mente percibir al mundo tal cual es. Dicha realidad es llamada, por algunos estudiosos, "de segundo grado" porque concierne no la realidad del mundo sino el significado que damos a dicha realidad. Por lo tanto, aun cuando somos conscientes que vivimos en un mundo ilusorio construido a través de imágenes, conceptos y modelos, es casi imposible romper la "esfera semiótica» que nos envuelve y distorsiona nuestra percepción. Esto porque olvidamos a menudo las etiquetas lingüísticas con las que aprendimos a nombrar las cosas, y consideramos los signos referenciales como si fueran reales. La experiencia del mundo, entonces, es reemplazada por una serie de inferencias conceptuales pseudo-objetivas que nos hace caer en la ilusión de no tener ilusiones (la misma que nos hace creer en una auto-identidad auténtica cuando, en su mayor parte, la identidad es - como bien ha dicho Borges - una imagen construida por la memoria). Se necesita una atención extrema e intensa de cada instante y un buen conocimiento de nuestras creencias y pre-conceptos conscientes y subconscientes para romper «la gran ilusión» de no tener ilusiones, y poder abrir brechas en la esfera semiótica (Cortázar las 
llamaba «fisuras»). El problema es que estamos demasiado distraídos en nuestro vertiginoso quehacer cotidiano para ser conscientes de las percepciones ilusorias ${ }^{16}$, y basta poco para que los fragmentos de la personalidad tomen el control de nuestra totalidad psíquica. Deberíamos seguir el consejo del místico evangelista del siglo XVII que decía: «Quien camina a través del desierto, a lo largo de senderos desconocidos, no debe continuamente mirarse a los lados y buscar todos los senderos secundarios, si no quiere perderse» (la traducción es mía) (Ruhbach y Sudbrack, 2003:114).

Volviendo entonces al cuento de Borges, la perspectiva hermética obliga a pensar en profundidad y a vivenciar la realidad en primera persona, con lo cual el episodio de la rosa no puede haber sido una experiencia puramente perceptiva y engañadora; se coloca, en cambio, como un fil rouge que conecta no solo al lector con su propio camino, sino también al Borges escritor con el sujeto itinerante Borges, pues este tuvo en su vida varias experiencias místicas que se encuentran desparramadas en forma alusiva ya en los años 30, en «Dos esquinas. Sentirse en muerte» y más tarde en varios relatos como en sus dos más autobiográficos: «El congreso del mundo» ${ }^{17}$ y este que analizamos, en el que podemos hipotizar en Paracelso una proyección del mismo Borges y de su maestro Macedonio. Era inútil, entonces, revelar al aspirante discípulo algo que todavía no había experimentado y que ni siquiera lograba vislumbrar con su intuición o con la fe. La alusión simbólica, y el lenguaje como poder creativo, en este caso se funden en la capacidad interpretativa del lector. Como ya he dicho en trabajos anteriores: «entender la metáfora hermética de Borges implica la comprensión del lenguaje alusivo de la dimensión trascendente que requiere un acto de fe, y también la del secreto protegido por Borges durante años y encerrado en los entretelones de su narración» (Ricci 2015:154). Es evidente que Borges buscó, durante años, el sentido trascendente del universo a través de la literatura, pero no solo en ella. Su búsqueda «infatigable» de la palabra como Absoluto, que lo asimila al misticismo cabalístico, recuerda estos versos paradójicos de «El Hacedor» (La cifra): «Ecos, resaca, arena, liquen, sueños./ Otra cosa no soy que esas imágenes/ que baraja el azar y nombra el tedio./ Con ellas, aunque ciego y quebrantado/ he de labrar el verso incorruptible/ y (es mi deber) salvarme». En Borges revive en parte, en estos versos, el Paracelso del cuento: sońoliento, distraído y fatigado, casi encadenado a un Paraíso presente que él quisiera transmitir pero sin éxito pues no encuentra al discípulo (lector) que intuya la Palabra Perfecta detrás de las palabras; al discípulo que se dé cuenta de que el camino o proceso creativo, es decir, la conexión entre el sujeto y Dios a través del lenguaje analógico/alusivo, es más importante que la meta. Lo repite también en «El etnógrafo» de Elogio de la sombra: «El secreto [...] no vale lo que valen los caminos que me condujeron a él. Esos caminos hay que andarlos» (TO, 1985:288). La meta como camino se entiende si consideramos que las palabras no sirven solo para comunicar, son también una fuente de energía; por eso, la unión que se produce al pronunciarlas constituye la búsqueda esencial del místico: no es casual que Paracelso en el cuento diga que el camino es la Piedra, y más adelante pronuncie la frase: «Sé que hay un Camino» (con la C mayúscula) (21).

La mente creativa de Borges ha renovado muchas veces, con textos complejos y meditados como «La escritura del Dios», «Las ruinas circulares», «El Aleph», «El 
Zahir», «El Sur», y a través de símbolos como el espejo, el laberinto, la rosa, la biblioteca circular, una circumambulatio alquímica constante, que habla al lector en forma alusiva y magistral, a través de dualidades especulares y juegos polisemánticos. Considerando que, hacia el final de su vida, Borges confesó haber sido visitado por el Espíritu cuatro o cinco veces (Ricci, 2011:221), la negación de Paracelso lleva a hipotizar que Borges hace actuar a Paracelso según las huellas de los maestros espirituales de todos los tiempos; por eso su lenguaje no explicita, solo sugiere lo que él ha experimentado como vivencia propia ${ }^{18}$. Es lo que el maestro exige al joven: esa fe imprescindible para un lenguaje alusivo ${ }^{19}$ que gran parte del mundo (y de los lectores) ha perdido. Por lo tanto, las referencias al Paraíso del presente y a la Rosa eterna pueden leerse como un desafío para el lector «despierto» en grado de superar las fronteras de la palabra y aspirar a una posible experiencia interior a través del silencio de lo no-dicho en los símbolos y metáforas de la vasta obra de Borges, en la cual es probable que él nos haya dejado como meta la posibilidad de tocar algo tan inagotable y misterioso como la Rosa infinita que abunda en sus textos poéticos.

${ }^{1}$ «El ser del hombre es una comunicación profunda. Ser significa comunicar. Ser significa ser para el otro y, a través del otro, para sí mismo. El hombre no posee un territorio "interior" soberano. Está integralmente y siempre en una frontera: mirando dentro sí mismo, mira en los ojos del otro o a través de los ojos del otro. No puedo prescindir del otro, no puedo devenir yo mismo sin el otro» (la traducción es mía). Citado por P.L. Crovetto en la Introducción a Todorov (1992).

${ }^{2}$ «A El Fluir. Este se presenta como un cambiamento constante, oscuro y magmático, radicalmente "destructivo". El segundo nivel, intermedio (B), es el de las conexiones, y se caracteriza por potencialidades o elementos alternativos. Por último, el nivel más alto (C), superpuesto a los otros dos, es el de las construcciones de la identidad [...] Por ser construcción, la identidad se presenta como una reducción drástica respecto a las posibilidades de conexión (B) y como un entumecimiento compacto respecto a la inevitabilidad del fluir (A). "De-cidir" la identidad es un "re-cortar" las conexiones (B) que de otro modo la frenarían y la sofocarían.» (la traducción es mía)

${ }^{3}$ El proceso de disonancias cognitivas es un ejemplo de invariante del funcionamiento psíquico, pues crea un movimiento de pensamiento o acción discordante que la mente tiende a eliminar mediante una acción más o menos creativa que le permita la resolución del conflicto. Este mecanismo se acentúa en el sujeto itinerante y hace que su identidad aumente progresivamente en complejidad, lo cual influirá a su vez en el ambiente, modificando los contextos que lo circundan.

${ }^{4}$ «Confluencia de orillas, lenguas y migraciones acuáticas en la literatura rioplatense del primer novecientos». En K. Alfons Knauth et al, Migrancy
} 
and Multilingualism in World Literature, Berlin: LIT Verlag 2016. Tomaré prestado algunos conceptos míos de este trabajo, relacionados con el tema que nos interesa. Para mayores detalles, consultar dicho trabajo.

${ }^{5}$ Darío y Lugones frecuentaron en París círculos esotéricos guiados por Gérard Encausse, más conocido como Papus, fundador del Ordre martiniste y del movimiento Rosacruz; son conocidos, además, los intereses teosóficos de Lugones, que lo llevaron a escribir textos como Las fuerzas extrañas. (Allegra, 1982:143)

${ }^{6}$ En Darío se ponen en evidencia en Los raros y en varios poemas de ese período, como «Lo fatal».

${ }^{7}$ La ciudad llegó a triplicar la población en poco más de veinte años y pasó de los 450.000 habitantes en 1880 a casi 1.600 .000 en 1914 , de los cuales la mitad inmigrantes y la otra mitad descendiente, en un $60 \%$, de inmigrantes Una verdadera invasión extranjera proveniente de Italia y España en su mayor parte, y de pequeños grupos también de Francia, Alemania, Rusia, Polonia, Turquía y algunos países de Oriente, sin olvidar el numeroso componente africano de esclavos libertos que influyó notablemente en la música.

${ }^{8}$ «Podría definirme como crítico-místico; ningún místico acreditó crítica; ningún metafísico, excepto Schopenhauer, poseyó la mística» ("No toda es vigilia la de los ojos abiertos». En O.C.1990:207). «El conocimiento de la actitud mística [...] es un "hecho" humano que ha importado mucho ciertamente, en excitar y quizá señalar un rumbo a mi obra propia» [...] «Por lo demás en general, no creo en transmisiones efectivas de doctrinas o verdades: lo único que la exposición puede es estimular...» (ibid.:212) ${ }^{9}$ En El idioma de los argentinos comenta: «El deber de cada uno es dar con su voz. El de los escritores más que nadie, claro que sí...Quisiéramos un español dócil y venturoso que se llevara bien con la apasionada condición de nuestros ponientes y con la infinitud de dulzura de nuestros barrios y con el poderío de nuestros veranos y nuestras lluvias y con nuestra pública fe. [... ] La esperanza es amiga nuestra y esa plena entonación argentina del castellano es una de las confirmaciones de que nos habla». (Borges 1994:150)

${ }^{10}$ Para mayor información sobre la vida de Borges y la influencia de sus diversas crisis y de las disciplinas herméticas en su literatura, remito a mi libro: G.N. Ricci, Las redes invisibles del lenguaje. La lengua en y a través de Borges, Buenos Aires: Dunken 2012.

${ }^{11}$ Shlomy Mualem (2007:152) coloca la primera edición en 1983: «La rosa de Paracelso se publicó en La memoria de Shakespeare en 1983». Sin embargo, su primera edición, publicada por Sedmay, con el título La rosa de Paracelso y Tigres azules, es de 1977. La edición que utilizo para este trabajo es de Ediciones Siruela, Madrid 1985 y lleva el título: Veinticinco Agosto 1983 y otros cuentos.

${ }^{12}$ «Nosotros, en realidad, somos Dios, y por lo tanto tenemos que experimentar por nosotros mismos lo que está enterrado en nosotros: Él es de sí mismo y no nuestro; nos ha hecho el cuerpo, dado la vida junto con la sabiduría y de Él provienen todas las cosas» (1998:24); «El hombre no aprende nada, sino que despierta e invoca solo lo que ya está en él» (31); 
«Así como en la tierra tenemos que tener en Dios nuestro espejo, [...] así en la Sabiduría tenemos que manifestar a Dios» (35); «Dios es poderoso y quiere manifestar su poder en el arte tanto a los hombres como a los ángeles» (41); «No debemos seguir a los antiguos, sino radicarnos en la fe y colocar y hacer crecer nuestra semilla bajo el sol». (98, la traducción es mía) ${ }^{13}$ Entre las doctrinas esotéricas podemos mencionar la alquimia, la cábala, la gnosis, las religiones mistéricas; en cada una de ellas, el secreto puede ser entendido o como algo inaccesible en relación con los mecanismos del macrocosmos, o como pacto de silencio de los iniciados hacia los profanos. ${ }^{14}$ La afirmación de Piglia hace venir a la memoria el artículo de Borges de 1932: «El arte narrativo y la magia», en el cual Borges habla de dos causalidades diferentes: «una natural, que es el resultado incesante de incontrolables e infinitas operaciones; el mágico, donde profetizan los pormenores, lúcido y limitado. En la novela, pienso que la única y posible honradez está con el segundo. Quede el primero para la simulación psicológica». Borges (1957), Discusión, Buenos Aires: Emecé 1989, p. 126. 15 «Insolente alarde de Paracelso, que hubiera querido resucitar de las cenizas la rosa o violeta original — que ahora resulta igualada en logros modernos» (la traducción es mía). Citado por Shlomy Mualem en «Borges y el lenguaje cabalístico: Ontología y simbolismo en La Rosa de Paracelso». En Variaciones Borges (2007:154).

${ }^{16}$ La ciencia ha confirmado los descubrimientos descritos por Aldous Huxley en su libro Las puertas de la percepción. El autor explica que la función del cerebro es la de reducir la percepción para no ser apabullado por el exceso de estímulos (cosa que está sucediendo actualmente con el exceso de videos y mensajes con los que la técnica nos está inundando). Lo que hacía el LSD era suprimir los filtros e inhibiciones del cerebro y, con ello, ampliar la percepción de la realidad.

${ }^{17}$ Cfr. G.N. Ricci, «El horizonte de la metáfora: ficción y metaficción en J.L. Borges». En S. Barei (compiladora), La cultura y sus retóricas, Universidad Nacional de Villa María 2017:131-157. Por falta de tiempo, no he podido explayarme en las características de la Cábala y de la Alquimia, por lo cual remito a mis trabajos de 2011, 2012, 2015 y 2017. ${ }^{18}$ Recordemos que la primera de ellas la describió en «Sentirse en muerte» (El idioma de los argentinos): «Me sentí muerto, me sentí percibidor abstracto del mundo: indefinido temor imbuído de ciencia que es la mejor claridad de la metafísica [...] Quede, pues, en anécdota emocional [...] el momento verdadero de éxtasis y la insinuación posible de eternidad de que esa noche no me fue avara» (1994:125-126). Cfr. También «Boletín de una noche toda» en Textos recobrados 1919-1929 (1997:185-186), que reenvía a la Nigredo alquímica, primera fase del Opus. Borges declaraba ser agnóstico ante el público, pero en realidad no lo era pues rezaba todas las noches, como aseguran algunos testigos cercanos (reenvío a mi libro del 2011: 209-233).

19 «Ahora he llegado a la conclusión (y esta conclusión puede parecer triste) que ya no creo en la expresión, solo creo en la alusión. Después de todo, ¿qué son las palabras? Las palabras son símbolos de una memoria compartida». (Borges 1984:33) 


\section{Referencias bibliográficas}

\section{Obras de Jorge Luis Borges consultadas}

Borges, J.L. (1993). El tamaño de mi esperanza. Seix Barral (1923).

Borges, J.L. (1989). Discusión. Emecé (1957).

Borges, J.L. (1994). El idioma de los argentinos. Seix Barral (1928).

Borges, J.L. (1970). El informe de Brodie. Emecé.

Borges, J.L. (1985). Veinticinco Agosto 1983 y otros cuentos. Siruela (1977).

Borges, J.L. (1985). Tutte le Opere (ed. bilingue a cura di D. Porzio). Mondadori (1974).

Borges, J.L. (1997). Siete Noches. Emecé (1980).

Borges, J.L. (1998). Biblioteca personal (prólogos). Alianza editorial (1988). Borges, J.L. (1989). Obras Completas. Emecé, 4 vols.

BoRges, J.L. (2001). Textos recobrados 1919-1929. Emecé.

\section{Libros principales consultados sobre el tema}

Alazraki, J. (1988). Borges and the Kabbalah and Other Essays on his Fiction and Poetry, Cambridge University Press.

Allegra G. (1982). Il regno interiore. Premesse e sembianti del Modernismo in Spagna. Jaka Book.

Assunção, F. (1998). El tango y sus circunstancias (1880-1920). El Ateneo. Balderston, D. (ed.) (2007). Variaciones Borges n. 23. The University of Iowa.

BAREI, S. (2017). La cultura y sus retóricas. Miradas interdisciplinarias. UNC y UNSM.

Carrizo, A. (1982). Borges el memorioso. Fondo de Cultura Económica. Fernández, M. (1990). Obras completas. Corregidor.

Galasso, N. (1998). La búsqueda de la Identidad Nacional en Jorge Luis Borges y Raúl Scalabrini Ortiz. Homo Sapiens.

INGHILleri, P. (1995). Esperienza soggettiva, personalità, evoluzione culturale. UTET.

Jung, C.G. (1977). Psicología y alquimia. Plaza \& Janés.

Knauth, K.A. y Ping-Hui Liao (eds.) (2016). Migrancy and Multilingualism World Literature. LIT.

Paracelso (1998). Il fondamento della sapienza. Il leone verde.

Piglia, R. (2001). Formas breves. Anagrama.

Remotti, F. (2001). Contro l'identità. Laterza.

Ricci, G.N. (2011). Las redes invisibles del lenguaje. La lengua en y a través de Borges, Dunken (2002).

Ricci, G.N. (2012). Il viaggio infinito. Tecniche e percorsi di trasformazione. Bonanno ed.

Rodríguez Monegal, E. (1993). Borges, una biografia literaria. Fondo de Cultura Económica.

Ruhbach, G. y J. Sudbrack (Ed.) (2003). Grandi mistici. Dal 300 al 1900. Ed. Dehoniane.

Scalabrini Ortiz, R. (1994). Tierra sin nada, tierra de profetas. Reconquista.

Seвeor, T. et al. (2001). Semiotica dellio. Meltemi. 
Cruzar las fronteras: el sujeto itinerante y las migraciones objetivas y subjetivas · G.N. Ricci

Sosnowski, S. (1976) Borges y la Cábala. Hispamérica.

Teitelboim, V. (1996). Los dos Borges. Sudamericana.

Todorov, T. (1992). La conquista dell'America. Einaudi.

VÁzQuez, M.E. (1996). Borges, esplendor y derrota. Tusquets.

Zimmermann, M. (2019). I luoghi più strani del mondo antico. Einaudi.

\section{Ricci, Graciela N.}

«Cruzar las fronteras: el sujeto itinerante y las migraciones objetivas y subjetivas». El hilo de la fábula. Revista anual del Centro de Estudios Comparados (20), 113-132. 